\title{
Solder joint reliability based on creep strain energy density for SAC305 and doped SAC solders
}

\author{
Ramiro Sebastian Vargas Cruz ${ }^{1, *}$, and Viktor Gonda ${ }^{2}$ \\ ${ }^{1}$ Óbuda University, Doctoral School on Materials Sciences, Bécsiút 96b, 1034 Budapest, Hungary \\ ${ }^{2}$ Óbuda University, Bánki Donát Faculty of Mechanical and Safety Engineering, Népszínház u. 8, \\ 1081 Budapest, Hungary
}

\begin{abstract}
Parallel to the development of new lead-free solders, electronic packaging has gone through a considerable evolution. A redistribution of layers allows the increase of functionality by increasing the number of inputs/outputsin the packagewhile reducing the size. The reliability of the package is strongly influenced by the reliability of the interconnects. During production and service life, there are thermal processes involved that may lead to thermal fatigue. In this work, a two-dimensional finite elementmodel of a Fan-Out Wafer Level Packaging (FO-WLP) was built, and simulations of thermal test cycles were carried out varying the solder interconnect material: SAC305, SACQ, SACR, orInnoLot. A thermal oscillating load from $-40^{\circ} \mathrm{C}$ to $125^{\circ} \mathrm{C}$ was applied to the packaging for three hours. State of the art concerning solder joint reliability models based on creep behavior reveals the benefit of using energy-based parameters, as cycles to failure are inversely proportional to the average creep strain energy density.Based on theaverage creep strain energy density simulation results, the reliability of the package withdifferent solderswas compared.The qualitative results suggestthat SACQ has a significant advantage in the operational lifetime compared toSACR, InnoLot, and SAC305.
\end{abstract}

\section{Introduction}

Recent regulations on Waste from Electrical and Electronic Equipment (WEEE) and Restrictions of Hazardous Substances (RoHS) have limited the usage of $\mathrm{Pb}$ (lead) in electronic applications [1], [2]. One of the critical lead-contained components in the electronics industry had been the soldering material; the eutectic $\mathrm{Sn}-\mathrm{Pb}$ (tin-lead) solderhad to be replaced by lead-free soldering materials. Typically, solder joints are subjected to temperatures around $80 \%$ of their melting temperature during their service life [3]. A significant change in the composition of the soldering material translates to an increase in the melting temperature that should not compromise the electronic device performance and reliability. One of the first alloy compositions that replaced lead-contained solders was the

*Corresponding author: ramiro.vargas@stud.uni-obuda.hu 
near eutectic Sn-Ag-Cu (tin-silver-coper), widely known as SAC solder[4]. Varying the composition of the alloys, different SAC solders have been commercialized (e.g., SAC305, SAC405, SAC105)[5]. In the automotive industry, thermal requirements have been defined for Integrated Circuits (ICs) that undergo harsh working environments where temperature loads may reach over $150^{\circ} \mathrm{C}$ [6]. Consequently, new solder materials, called doped-SAC or SAC-X, were developed[7].

Currently, electronic equipment reliability is linked to performance and security [8]. Therefore, it is essential to understand reliability tests and mathematical models that can effectively predict the lifetime of materials. Regarding thermal cycling reliability tests, recent studies have proved the accuracy of Finite Element Analysis (FEA) on ICs simulations with lifetime prediction errors of less than $20 \%$ [9].Lead-free solder joint reliability is of great interest to accurately predict the service life of an electronic device.

In this work, a two-dimensional finite element model of a Fan-Out Wafer Level Packaging (FO-WLP) was built, and simulations of thermal test cycles were carried out varying the solder interconnect material: SAC305, SACQ, SACR, or InnoLot. State of the art concerning solder joint reliability models based on creep behavior reveals the benefit of using energy-based parameters. Based on the average creep strain energy density simulation results, the reliability of the package with different solders was compared. The qualitative results suggest that SACQ has a significant advantage in the operational lifetime compared to SACR, InnoLot, and SAC305.

\section{Reliability and material models for solder joints}

Reliability of ICs subjected to cycling thermal loads has been a core topic of research, with thermal fatigue analysis by predictions of the number of cycles to failure.

Initially, Distance to Neutral Point (DNP) was identified as a key parameter; hence the farthest solder joint from the neutral point of the IC possesses a risk due to the highest thermo-mechanical loads and a geometry that limits the size of the packaging and number of I/Os[10]. However, the accuracy of the approach has been intensely discussed because electronic packaging layouts have been improved. Lau[11]reported that the DNP approach presents some limitations. For instance, DNP failure prediction has been proved to be valid for packaging without underfill; however, it has been incorrectly applied where underfillis used[12].

The state of the art of reliability models used for solder joint reliability is summarized in Table 1. The number of cycles before failure is related either to strain or energy type of parameters. Li et al.[13] successfully conducted a simulation to evaluate the thermal fatigue life of a SAC solder material. Creep strain and creep strain energy density were used for the lifetime prediction. From the results, creep strain energy density using hyperbolic-sine model approached more accurately to experimental data.

According to Norris et al.[14], constant $n$ was observed to be 2 for most of metals. Zubelewicz et al.[15] stressed that Coffin-Manson law does not fit experimental data for high strain rates. Recently, Clech[16] summarized researches that compare the CoffinManson model and critical Distance to Neutral Point (DNP).

Pang et al. [17] presented research where tables for $n, n^{\prime}, C$ and $A$ are listed. Additionally, they included a new approach that includes frequency dependency.

Syed[18] proposed employing the Monkman-Grant model to predict the number of cycles to failure based on accumulated creep strain and creep strain energy density per cycle. Using the Power-law and Hyperbolic-sine creep model, his founding demonstrates that both accumulated creep and energy density can effectively predict the lifetime of solder stacks. 
Although the Darveaux model was not available in commercial simulation programs, his approach was later corroborated to be more accurate than the Coffin-Manson model by Ramachandran et al.[19].

Table 1. Overview of solder joint reliability models.

\begin{tabular}{|c|c|}
\hline Model & Variable's description \\
\hline $\begin{array}{l}\text { Coffin-Manson [20] } \\
\qquad N_{f}\left(\Delta \epsilon_{p}\right)^{n}=C\end{array}$ & $\begin{array}{l}N_{f}(-), \text { Cycles to failure. } \\
n(-), \text { Empirical constant. } \\
\Delta \epsilon_{p}(-), \text { Inelastic strain range. } \\
C(-), \text { Proportionality factor / Fatigue ductility coefficient. }\end{array}$ \\
\hline $\begin{array}{l}\text { Morrow[21] } \\
N_{f}{ }^{\prime} W_{p}=A\end{array}$ & $\begin{array}{l}n^{\prime}(-), \text { Fatigue exponent. } \\
A\left(\mathrm{MJ} / \mathrm{m}^{3}\right), \text { Material ductility coefficient. } \\
W_{p}(\mathrm{MPa}), \text { Inelastic strain energy density. }\end{array}$ \\
\hline $\begin{array}{l}\text { Monkman-Grant[22] } \\
\qquad t_{r}=\frac{\varepsilon_{f}}{\dot{\varepsilon}_{c r}}\end{array}$ & $\begin{array}{l}t_{r}(\mathrm{~s}), \text { time to rupture. } \\
\varepsilon_{f}(-), \text { creep ductility. } \\
\dot{\varepsilon}_{c r}\left(\mathrm{~s}^{-1}\right), \text { creep strain rate. } \\
\end{array}$ \\
\hline Darveaux et al.[23] & \\
\hline $\begin{array}{c}\begin{array}{c}\text { Crack Initiation } \\
N_{0}=K_{1} \Delta W_{\text {ave }}{ }^{K_{2}}\end{array} \quad \begin{array}{l}\text { Crack Growth } \\
\text { Energy Density Model } \\
\text { En }\end{array}=K_{3} \Delta W_{\text {ave }}{ }^{K_{4}} \\
N_{f}=N_{0}+\frac{a}{\left(\frac{d A}{d N}\right)}\end{array}$ & $\begin{array}{l}N_{0}(-), \text { Number of cycles before crack initiation. } \\
\Delta W_{\text {ave }}(\mathrm{MPa}), \text { Average strain energy density. } \\
\frac{d a}{d N}(\mathrm{~m} / \text { cycle }), \text { Crack growth rate per cycle. } \\
a(\mathrm{~m}), \text { Critical length exposed to crack propagation. } \\
K_{1-4}, \text { Constants based on the element size of the solder. }\end{array}$ \\
\hline
\end{tabular}

For creep material models, either hyperbolic-sine law or Anand's type of models are often used. A more detailed list of creep-based material characterization experiments is summarized in Table 2. The authors who used the hyperbolic-sine model stressed the lack of articles reporting Anand's constants.

Table 2. Employed creep and reliability models in highlighted references.

\begin{tabular}{|l|c|c|c|c|c|}
\hline \multirow{2}{*}{\multicolumn{1}{|c|}{ Author }} & \multicolumn{2}{c|}{ Creep Model } & \multicolumn{3}{c|}{ Reliability Model } \\
\cline { 2 - 6 } & Hyperbolic Sine & Anand & Morrow & Darveaux & Coffin Manson \\
\hline Lui et al. [10] & & $\times$ & $\times$ & & \\
\hline Che [24] & $\times$ & & $\times$ & & \\
\hline Chen [25] & $\times$ & & & & \\
\hline Guven[26] & & $\times$ & & $\times$ & \\
\hline Lin [27] & $\times$ & $\times$ & $\times$ & & \\
\hline Che and Pang [28] & & $\times$ & $\times$ & & \\
\hline Rahangadale et al. [29] & & & $\times$ & & \\
\hline
\end{tabular}

\section{Simulation Methods}

Finite Element Analysis (FEA) has been successfully applied for package reliability analysis [30]. According to Gokhale et al.[30], Computer-Aided Engineering (CAE) can predict failures with a $90 \%$ accuracy.

An Integrated CircuitS-PBGA-N167 from the Texas Instrument [31]in an advanced Fan-Out Wafer Level Packagingwas used as the base for the 2-D finite element model.Half of the package was modeled. Boundary conditions on the left edge were applied for symmetry with constrained displacements in the $x$-direction. A vertical constrain was 
placed to the left bottom corner concerning the $y$-direction displacementsto ensure a unique mathematical solution (see Fig. 1). The IC comprises nine different materialsdetailed in Fig. 1.Corresponding material properties are listed in Table 3 for most constituents, except for the solders, which are shown in Table 4.
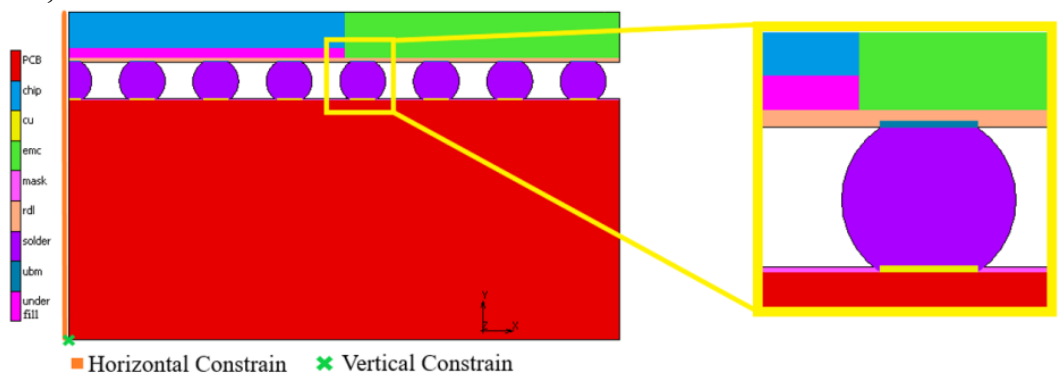

Fig. 1. 2D Model (Half cross-section of the chip).

Table 3. Material parameters [25].

\begin{tabular}{|c|c|c|c|c|}
\hline Material & Young's Modulus(GPa) & Poisson's Ratio & $\mathrm{CTE}^{1}\left(\mathrm{ppm} /{ }^{\circ} \mathrm{C}\right)$ & $\operatorname{Tg}^{2}\left({ }^{\circ} \mathrm{C}\right)$ \\
\hline Si (chip) & 131 & 0.3 & 2.8 & \\
\hline EMC & $\mathrm{T}<\mathrm{Tg}: 18.5 ; \mathrm{T}>\mathrm{Tg}: 1.2$ & 0.3 & T<Tg: 9;T>Tg: 18 & 163 \\
\hline Dielectrics & $\mathrm{T}<\mathrm{Tg}: 0.92 ; \mathrm{T}>\mathrm{Tg}: 0.1$ & 0.3 & $\begin{array}{c}\text { T < Tg: } 80 \\
\text { T > Tg: } 227\end{array}$ & 205 \\
\hline $\mathrm{Cu}$ & 117 & 0.34 & 17 & \\
\hline Underfill & $\mathrm{T}<\mathrm{Tg}: 3.8 ; \mathrm{T}>\mathrm{Tg}: 0.125$ & 0.3 & T< < Tg: 44; T > Tg: 119 & 141 \\
\hline Solder Mask & $\mathrm{T}<\mathrm{Tg}: 2.4 ; \mathrm{T}>\mathrm{Tg}: 0.23$ & 0.3 & $\mathrm{~T}<\mathrm{Tg}: 60 ; \mathrm{T}>\mathrm{Tg}: 161$ & 100 \\
\hline $\begin{array}{l}\text { PCB (Printed } \\
\text { Circuit Board) }\end{array}$ & For $\mathrm{x}, \mathrm{y}: 25$; For $\mathrm{z}$ : 11 & $\begin{array}{c}\text { For xy0.11 for } \\
\text { xz, yz0.39 }\end{array}$ & For $\mathrm{x}, \mathrm{y}: 15$ For $\mathrm{z}: 46$ & \\
\hline
\end{tabular}

${ }^{1}$ Coefficient of Thermal Expansion, ${ }^{2}$ Glass Transition Temperature

Table 4. Material parameters for the Anand creep model.

\begin{tabular}{|c|c|c|c|c|}
\hline Description & SACQ[32] & SACR[33] & InnoLot[33] & SAC 305[34] \\
\hline$s_{0}(\mathrm{MPa})$ & 0.405 & 34.72 & 32.42 & 21 \\
\hline $\mathrm{A}\left(\mathrm{s}^{-1}\right)$ & $2.45 \cdot 10^{8}$ & 1000 & 25000 & 3501 \\
\hline$\xi$ & 0.068 & 6 & 7 & 4 \\
\hline $\mathrm{m}$ & 0.36 & 0.15 & 0.35 & 0.25 \\
\hline$h_{0}(\mathrm{MPa})$ & 3521.56 & 145640 & 88875 & 180000 \\
\hline$\hat{s}(\mathrm{MPa})$ & 0.638 & 71.71 & 56.76 & 30.2 \\
\hline $\mathrm{n}$ & 0.0056 & 0.001 & 0.0097 & 0.01 \\
\hline $\mathrm{a}$ & 1.243 & 1.55 & 1.45 & 1.78 \\
\hline$Q\left(\mathrm{~J} \cdot \mathrm{mol}^{-1}\right)$ & 112313.8 & 92290.52 & 89313.9 & 77490.78 \\
\hline
\end{tabular}

For solder materials, four types were selected in this study: SACQ, SACR, InnoLot, and SAC305. The chemical compositions of the solder alloys are shown in Table 5 for comparison. The visco-plastic mechanical model was employed for the solder behavior in the form of Anand's creep model[35]. Anand properties for each used solder are detailed in Table 4.

Table 5. Chemical composition (wt $\%$ ) of some selected SAC solders.

\begin{tabular}{|c|c|c|c|c|c|c|}
\hline Solder & Sn & Ag & $\mathbf{C u}$ & $\mathbf{B i}$ & $\mathbf{N i}$ & $\mathbf{S b}$ \\
\hline SAC-R[33] & 96.62 & 0.00 & 0.92 & 2.46 & 0.00 & 0.00 \\
\hline SAC-Q[33] & 92.77 & 3.41 & 0.52 & 3.30 & 0.00 & 0.00 \\
\hline InnoLot[33] & 90.95 & 3.80 & 0.70 & 3.00 & 0.15 & 1.40 \\
\hline SAC305[36] & $95-96$ & $3.8-4.2$ & $0.3-0.7$ & 0.00 & 0.00 & 0.00 \\
\hline
\end{tabular}


An oscillating thermal load from $-40^{\circ} \mathrm{C}$ to $125^{\circ} \mathrm{Cwith}$ tree cycles was used, with a ramp-up time of 15 minutes, a dwell time of 15 minutes, a cooling time of 15 minutes, and another dwell time of 15 minutes, altogether 3 hours.

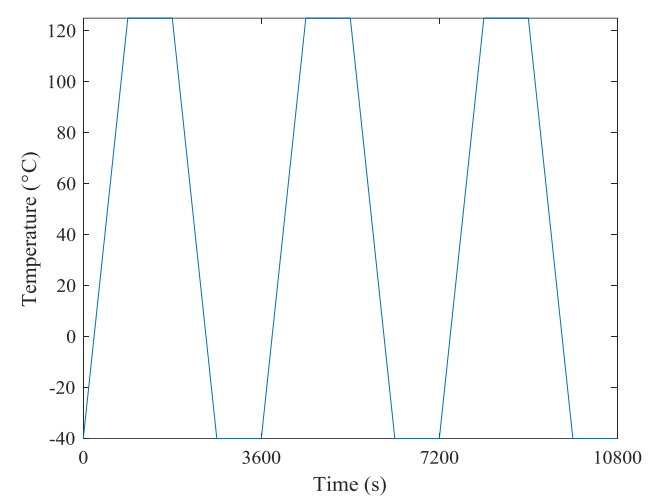

Fig. 2.Thermal Load.

Multicriteria time stepping was selected for the load cases ( 3 load cases of $3600 \mathrm{~s}$ each) with fine criteria conditions to assure a minimum of 100 steps per thermal cycle.

\section{Results}

Creep strain energy density (CSED) data was collected from the four simulation replicates. The bottom corner locations of each solder ball displayed a high CSED for all the scenarios. The location with the most critical value of CSED (see Fig. 3) was situated in the bottom right corner of the outer solder ball(the most distant point from the line of symmetry).

As the multi-criteria was utilized for time-stepping, each CSED vs. time curve presenteda different number of points: SAC305, 1808 points; SACQ, 4135points;InnoLot, 1669 points; and $S A C R, 579$ points. The number of points was directly proportional to the simulation time that varied from nearlyone hour to over five hours.

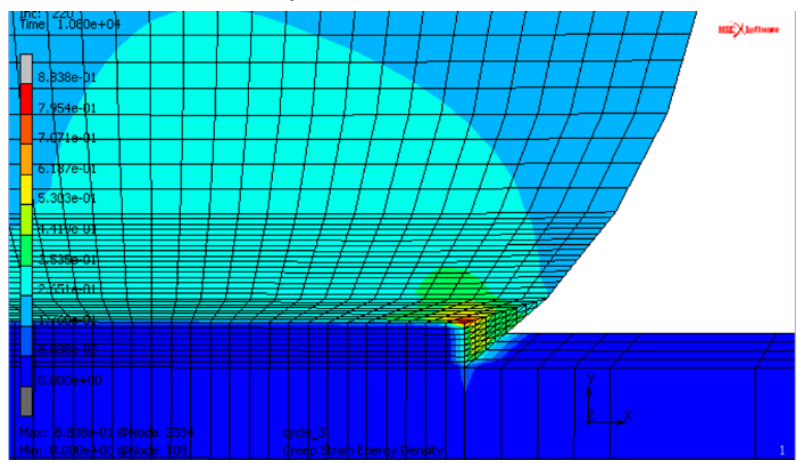

Fig. 3. Creep Strain Energy Density - Contour Band at the critical location (SAC305).

The CSED vs. time curves from the critical location (Fig. 3) of each replicate were summarized in Fig 4. It is worth noting that SACQ presents the lowest CSED accumulation among the different soldering materials and the highest expected resolution due to a large number of steps. Additionally, InnoLot and SAC305 curves display a similar behavior during the first two thermal cycles. Nevertheless, the approximation of the average of 
CSED only considers the CSED subtraction between the third and second thermal cycle (calculated in Table 6).

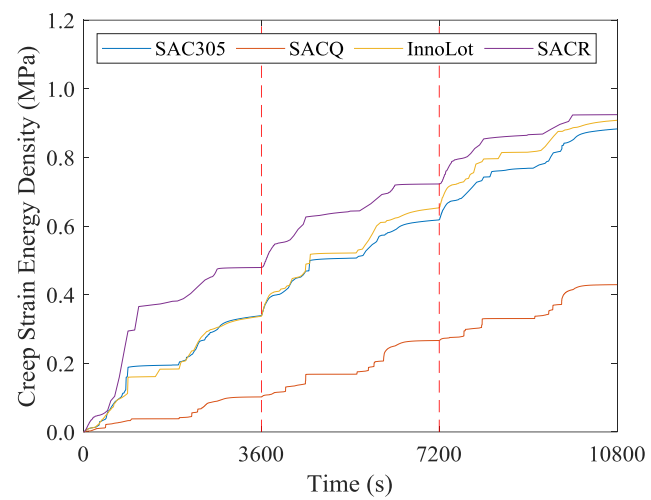

Fig. 4. Creep Strain Energy Density Comparison.

The aim of the comparison addresses creep-based reliability. From Table 1, Morrow's model was selected following the authors' trend in Table 2. Morrows's model requires the average creep strain energy density, $\Delta W_{a v}$, as a key parameter of the number of cycles to failure calculation. According to Che and Pang[28], three thermal cycles are enough to obtain a stable plastic work density that approximates the average creep strain energy density. It can be computed by taking the values at the end of the third and second thermal cycle as detail in Eq. (1).

Calculation of average creep strain energy density $\left(\Delta W_{a v}\right)[28]$ :

$$
\Delta W_{a v}=W_{3^{\mathrm{rd}} \mathrm{TC}}-W_{2^{\text {nd }} \mathrm{TC}}
$$

Where: $\Delta W_{a v}$, average creep strain energy density; $W_{3^{\text {rd }} \mathrm{TC}}$ and $W_{2^{\text {nd }} \mathrm{TC}}$ Creep strain energy density at the end of the third and second thermal cycle (TC), respectively.

The computed approximation of average CSED shows that SACQ presents the lowest value, whereas SAC305 displays the highest value (see Table 6).Based on Morrow'sreliability modelpresented in Table 1, the number of cycles to failure is inversely proportional to the average of CSED. Therefore, SACQ would resist the most extended working lifetime, followed by SACR, InnoLot,and SAC305. These results agree with a similar experimental comparison performed by Wei et al. [37] where SAC305 endured the least number of cycles to failurethan SACQ, SACR, and InnoLot, under stress-controlled conditions.

Table 6. Approximation of the Average of Creep Strain Energy Density (MPa).

\begin{tabular}{|c|c|c|c|c|}
\hline CSED & SAC305 & SACQ & InnoLot & SACR \\
\hline Cycle 1 & 0.339020 & 0.102072 & 0.337066 & 0.479284 \\
\hline Cycle 2 & 0.617905 & 0.266476 & 0.653259 & 0.722654 \\
\hline Cycle 3 & 0.883068 & 0.429206 & 0.908353 & 0.924602 \\
\hline $\boldsymbol{\Delta W a v}$ & 0.265163 & 0.162730 & 0.255094 & 0.201948 \\
\hline
\end{tabular}

\section{Conclusions}

Reliability of an advanced electronic package is strongly influenced by the reliability of the interconnects. In this work, a two-dimensional finite element model of a Fan-Out Wafer 
Level Packaging was built, and simulations of thermal test cycles were carried out varying the solder interconnect material: SAC305, SACQ, SACR, or InnoLot.

State of the art concerning solder joint reliability models based on creep behavior reveals the benefit of using energy-based parameters, as cycles to failure are inversely proportional to the average creep strain energy density.

Based on the average creep strain energy density simulations results, the reliability of the package with different solders was compared,and the following conclusions are drawn:

1. The critical location regarding CSED is commonly situated at the most outer solder ball. This conclusion strengthens the Distance to Neutral Point theory.

2.Doped SAC solders are more advantageous than SAC305 solder in terms of a working lifetime, as the simulation results agreed with similar experimental comparisons.

3. The qualitative results suggest that SACQ has a significant advantage in the operational lifetime compared to SACR, InnoLot, and SAC305.

\section{References}

1. R. Chandrappa, D. B. Das, Waste from Electrical and Electronic Equipment, 197-216 (2012)

2. EUROPEAN PARLIAMENT; THE COUNCIL OF THE EUROPEAN UNION, Directive 2002/95/EC of the European Parliament and of the Council of 27 January 2003 on the restriction of the use of certain hazardous substances in electrical and electronic equipment, Official Journal of the European Union (2003)

3. T. R. Bieler, T. K. Lee, Lead-Free Solder, Reference Module in Materials Science and Materials Engineering (2017)

4. K. Suganuma, Curr. Opin. Solid State Mater. Sci., 5, 55-64 (2001)

5. H. Ma, J. C. Suhling, J. Mater. Sci., 44, 1141-1158 (2009)

6. R. W. Johnson, J. L. Evans, P. Jacobsen, J. R. R. Thompson, M. Christopher, IEEE Trans. Electron. Packag. Manuf., 27, 164-176 (2004)

7. I.E. Anderson, J Mater Sci: Mater Electron, 18, 55-76 (2007)

8. K. Seshan, Reliability Issues, Handbook of Thin Film Deposition, Elsevier, 43-62 (2018)

9. H. Zhang, F. Che, T. Lin, W. Zhao, Stress and reliability analysis for interconnects, Modeling, Analysis, Design, and Tests for Electronics Packaging beyond Moore, Elsevier, 131-244 (2020)

10. T. C. Lui, B. N. Muthuraman, THERMINIC 2016, Reliability assessment of wafer level chip scale package (WLCSP) based on distance-to-neutral point (DNP), (Budapest, Hungary, 2016)

11. J. H. Lau, Solder. Surf. Mt. Technol., 9 (2), 58-60 (1997)

12. W. Dauksher, W. S. Burton, Microelectron. Reliab., 43 (12), 2011-2020 (2003)

13. X. Li, Z. Wang, J. Mater. Process. Technol., 183 (1), 6-12 (2007)

14. K. C. Norris, A. H. Landzberg, IBM J. Res. Dev., 13 (3), 266-271 (1969)

15. A. Zubelewicz, R. Berriche, L. M. Keer, M. E. Fine, Am. Soc. Mech. Eng., 111, 179182 (1988)

16. J. Clech, SMTA International 2016, The Combined Effect of Assembly Pitch and Distance to Neutral Point on Solder Joint Thermal Cycling Life, (Rosemont, USA, 2016)

17. J. H. L. Pang, B. S. Xiong, T. H. Low, Thin Solid Films, 462-463 (SPEC. ISS.), 408$412(2004)$

18. A. Syed, ECTC 2004, Accumulated creep strain and energy density based thermal fatigue life prediction models for SnAgCu solder joints, (Las Vegas, USA, 2004)

19. V. Ramachandran, K. C. Wu, K. N. Chiang, J. Mech., 34 (5), 637-643 (2018) 
20. S. S. Manson, Thermal Stress and low-cycle fatigue (1966)

21. J. Morrow, Cyclic Plastic Strain Energy and Fatigue of Metals, Internal Friction, Damping, and Cyclic Plasticity, ASTM International, 45-87 (1965)

22. F. C. Monkman, N. J. Grant, American society of testing materials, Proceedings, 56, 593-620 (1956)

23. R. Darveaux, K. Banerji, A. Mawer, G. Dody, J. Lau, Reliability of plastic ball grid array assembly, Ball grid array technology, 13, 379-442 (1995)

24. F. X. Che, EPTC 2016, Study on board level solder joint reliability for extreme large fan-out WLP under temperature cycling (Singapore, 2016)

25. Z. Chen et al., EPTC 2018, Solder Joint Reliability Simulation of Fan-out Wafer Level Package (FOWLP) Considering Viscoelastic Material Properties (Singapore, 2018)

26. I. Guven, V. Kradinov, J. L. Tor, E. Madenci, J. Electron. Packag. Trans. ASME, 126 (3), 398-405 (2004)

27. W. Lin, Q. Pham, B. Baloglu, M. Johnson, ECTC 2017, SACQ Solder Board Level Reliability Evaluation and Life Prediction Model for Wafer Level Packages (Orlando, USA, 2017)

28. F. X. Che, J. H. L. Pang, EPTC 2004, Thermal fatigue reliability analysis for PBGA with Sn-3.8Ag-0.7Cu solder joints (Singapore, 2004)

29. U. Rahangdale et al., ITHERM2017, Mechanical characterization of RCC and FR4 laminated PCBs and assessment of their board level reliability, (Orlando, USA, 2017)

30. N. S. Gokhale, S. Deshpande, S. Bedekar, A. Thite, Practical finite element analysis (Finite to infinite, Maharashtra, 2008)

31. Texas Instruments Incorporated, MicroStar BGA, Packaging Reference Guide (2000)

32. T. C. Lui, IWIPP2017, Lifetime prediction of viscoplastic lead-free solder: A new solder material, SACQ (Delft, Netherlands, 2017)

33. S. Ahmed, M. Basit, J. C. Suhling, P. Lall, ASME 2015 IEPTCE, Characterization of Doped SAC Solder Materials and Determination of Anand Parameters (San Francisco, USA, 2015)

34. M. Basit, M. Motalab, J. C. Suhling, P. Lall, ASME 2015 IEPTCE, Viscoplastic Constitutive Model for Lead-Free Solder Including Effects of Silver Content, Solidification Profile, and Severe Aging (San Francisco, USA, 2015)

35. L. Anand, J. Eng. Mater. Technol., 104 (1), 12 (1982)

36. K. Seelig, D. Suraski, [Online] Available: https://aimsolder.com [Accessed 20 April 2021]

37. X. Wei, S. Su, S. Hamasha, H. Ali, J. Suhling, P. Lall, ITHERM2020, Fatigue Performance of Doped SAC Solder Joints in BGA Assembly (Orlando, USA, 2020) 